6 - ORIGINAL ARTICLE

ISCHEMIA-REPERFUSION

\title{
Metformin attenuated the inflammation after renal ischemia/reperfusion and suppressed apoptosis of renal tubular epithelial cell in rats ${ }^{1}$
}

\author{
Zhi-shun Wang', Xiu-heng Liu', Min Wang ${ }^{\text {III }}$, Guan-jun Jiang ${ }^{\mathrm{III}}$, Tao Qiu ${ }^{\mathrm{III}}$, Zhi-yuan Chen ${ }^{\mathrm{III}}$, Lei Wang ${ }^{\mathrm{III}}$ \\ DOI: http://dx.doi.org/10.1590/S0102-865020150090000006
}

IPhD, Department of Urology, Renmin Hospital of Wuhan University, Hubei, China. Conception and design of the study, acquisition and analysis of data, manuscript writing.

IIPhD, Full Professor, Department of Urology, Renmin Hospital of Wuhan University, Hubei, China. Design of the study, critical revision, supervised all phases of the study.

IIIPhD, Physician, Department of Urology, Renmin Hospital of Wuhan University, Hubei, China. Acquisition of data.

\begin{abstract}
PURPOSE: To investigate the effect of metformin on renal tubular epithelial cell apoptosis and inflammation after kidney ischemia/ reperfusion in rats.

METHODS: Eighteen SD rats were randomly divided into three groups: Sham (S), Ischemia/reperfusion (I/R), and Metformin (E). Before establishing the I/R model, group $\mathrm{E}$ was administered metformin for three days, while groups $\mathrm{S}$ and $\mathrm{I} / \mathrm{R}$ were administered equal volumes of saline. After three days, a right nephrectomy was performed on all groups, after which the left kidneys of groups E and I/R rats were subjected to $45 \mathrm{~min}$ renal ischemia. Renal function, histology, and cell apoptosis were assessed. AMPK, pAMPK, COX-2, and Caspase 3 were also detected.

RESULTS: Compared to I/R group, Caspase 3 and COX-2 levels were decreased in group E. COX-2, Caspase3 and pAMPK levels were higher in groups $\mathrm{E}$ and $\mathrm{I} / \mathrm{R}$ than in group $\mathrm{S}$. The pAMPK level of group $\mathrm{E}$ was higher than that of I/R group, while COX-2 and caspase 3 were lower in group $\mathrm{E}$ than they were in the other groups. There was no significant difference between $\mathrm{E}$ and $\mathrm{I} / \mathrm{R}$ groups in AMPK levels.
\end{abstract}

CONCLUSION: Metformin preconditioning attenuated the inflammation caused by ischemia/reperfusion and inhibited the apoptosis of renal tubular epithelial cells.

Key words: Metformin. Ischemia. Reperfusion. Inflammation. Apoptosis. Kidney. Rats. 


\section{Introduction}

Kidney ischemia-reperfusion (I/R) injury is a common clinical, pathological process. Acute renal failure is a clinical disease, which occurs in 5\% of the total incidences of hospitalized patients and reaches $25 \%$ in severe illness ${ }^{1}$. Ischemia is the main cause of acute renal failure, and it causes injury to the kidney. Although the recovery of blood flow is essential for the survival of ischemic kidney tissue, this may paradoxically cause additional damage to the kidney. Renal tubular epithelial cell apoptosis is the main pathophysiological change that occurs in $I / R$, and it determines the extent of damage to the kidney function.

Adenosine monophosphate (AMP)-activated protein kinase (AMPK), contributes to meeting the energy requirements of ischemic tissue by inhibiting synthesis metabolism, promoting catabolism, and increasing the synthesis of adenosine triphosphate (ATP) while reducing its consumption. It has been confirmed that metformin relieves inflammatory responses following cardiac ischemia and protects cardiac function by activating $\mathrm{AMPK}^{2}$. It has also been proven that AMPK agonist alleviate the ischemia/reperfusion injury of renal epithelial cells in vitro and in animals such as Sprague-Dawley (SD) rats and canines ${ }^{3,4}$. Furthermore, AMPK agonists have anti-inflammatory effects, which inhibit the expression of inflammation factors such as tumor necrosis factor (TNF)- $\alpha$, interleukin (IL)-6, and cyclooxygenase $(\mathrm{COX} 2)^{5-7}$. Studies have proven that COX2 is associated with aggravation of inflammatory responses in numerous diseases ${ }^{8,9}$ including kidney $\mathrm{I} / \mathrm{R}$ injury ${ }^{10}$. Moreover, it has been verified that the expression level of COX2 increased after I/R in the kidney of rats ${ }^{11}$ while inhibition of COX2 was beneficial and improved renal function ${ }^{10}$.

Metformin may aggravate renal insufficiency, which in its severe form is a contraindication for the administration of metformin. However, we hypothesized that low doses of metformin may attenuate renal I/R injury by increasing the energy supply to the ischemic tissue and reducing the expression of inflammatory cytokines. Furthermore, the simultaneous occurrence of these metformin-induced actions may be beneficial and further protect the renal function.

\section{Methods}

The experimental animal protocol used in our study was approved by the Animal Ethics Review Committee of the Wuhan University, and the procedures were carried out accordance with the recommendations in the Guide for the Care and Use of Laboratory
Animals of the National Institutes of Health (NIH, Bethesda, MD, USA). Rats were kept in an air-filtered, homoiothermal $\left(20-22^{\circ} \mathrm{C}\right)$, and light-controlled ( 8 a.m. -8 p.m.) room, and allowed free access to a standard diet.

Eighteen healthy adult male SD rats, weighing 220 $250 \mathrm{~g}$ were provided by the Experimental Animal Center of the Medical College of Wuhan University (Wuhan, China). The rats were anesthetized by intraperitoneal (ip) injection of pentobarbital $(50 \mathrm{mg} / \mathrm{kg})$, administered $500 \mathrm{U}$ of heparin ip, and then placed on an electric heating pad to maintain their body temperature at $37^{\circ} \mathrm{C}$. The rats were divided into three groups using a random number table $(n=6)$. The groups included the sham operated (S), I/R, and metformin (E) groups. All the groups underwent a right nephrectomy while the $\mathrm{I} / \mathrm{R}$ group alone was further subjected to $45 \mathrm{~min}$ of renal ischemia of left the kidney after which the renal arteriovenous perfusion was restored. For 3 days prior to establishing the I/R model, group E was administered metformin $\left(0.125 \mathrm{mg} \cdot \mathrm{kg}^{-1} \cdot \mathrm{d}^{-1}\right.$, ip) while the $\mathrm{S}$ and $\mathrm{I} / \mathrm{R}$ groups were administered the same volume of normal saline.

\section{Reagents and drugs}

The cell apoptosis detection kit was purchased from Roche Co., Ltd (Basel, Switzerland), while the polyclonal rabbit anti-rat antibodies against caspase 3, AMPK, pAMPK, and COX2 were all purchased from Santa Cruz Biotechnology (Santa Cruz, CA). The rabbit anti-rat $\beta$-actin monoclonal antibody and horseradish peroxidase (HRP)tagged goat anti-rabbit IgG antibody were both purchased from the Beijing Zhongshan Golden Bridge Biotechnology Co., Ltd. The SC-2048 enhanced chemiluminescence (ECL) kit, and metformin were purchased from Santa Cruz Biotechnology (Santa Cruz, CA) and Sigma-Aldrich Corp. (St. Louis, USA), respectively.

\section{Detection of blood urea nitrogen (BUN) and creati- nine $(\mathrm{Cr})$}

After a 24-h reperfusion, all the rats were euthanized and 5-mL blood samples were collected from the inferior vena cava, and centrifuged for the determination of concentration of blood urea nitrogen (BUN) and creatinine $(\mathrm{Cr})$. These parameters were measured in the blood using standard techniques with an Olympus AU 2700 Analyzer (Olympus Optical Co., Ltd., Tokyo, Japan). 


\section{Hematoxylin and eosin (H\&E) staining and immu-} nohistochemical analysis

After the blood samples had been collected, the left kidneys of all rats were harvested, and tissue samples were fixed with $4 \%$ paraformaldehyde, embedded in paraffin according to standard procedures. Then the tissue was sectioned onto slides, gradually deparaffinized, rehydrated, and subsequently observed using hematoxylin and eosin (H\&E) staining. The morphological assessment was performed by an experienced renal pathologist who was blinded to the experimental grouping, using standard methodology. The histological grading standard used was the Jablonski grade ${ }^{12}$, which was classified into levels 0-4. A StreptAvidin-Biotin Complex (SABC) immunohistochemical staining kit was used to detect the expression of COX2 and Caspase-3, and all steps were performed strictly adhering to the manufacturer's instructions. Furthermore, we determined the expression rate and spatial distribution of the COX-2 and Caspase-3 positive cells.

\section{Determination of cell apoptosis}

To observe cell apoptosis induced by ischemia, an in-situ apoptosis detection kit (Promega, USA) was used and a terminal deoxynucleotidyl transferase dUTP nick end labeling (TUNEL) assay was performed following the manufacturer's instructions. The normal and apoptotic cell nuclei were blue-green and different shades of brown, respectively. Five high-power fields of vision in the distribution areas of the apoptotic cells in each slide were chosen, and the average number of apoptotic cells per 100 cells was calculated. The apoptotic index (AI) was expressed as a percentage $(\%)$.

\section{Western blot analysis}

The kidney tissue protein samples were extracted and quantitated using the bicinchoninic acid (BCA) assay, and stored at $-70^{\circ} \mathrm{C}$ until analyzed. Briefly, protein samples were prepared and separated $(50 \mu \mathrm{g} /$ lane $)$ using $10 \%$ sodium dodecyl sulfate-polyacrylamide gel electrophoresis (SDSPAGE) and then transferred to a nitrocellulose membrane (Bio-Rad). The membrane was blocked with 5\% nonfat dry milk in Tris-buffered saline plus Tween (TBST) buffer and then incubated with polyclonal primary antibodies against caspase-3, COX-2, AMPK, and pAMPK (1:100 each) and monoclonal rabbit anti-rat $\beta$-actin $(1: 2000)$ overnight at $4{ }^{\circ} \mathrm{C}$. After extensively washing the membranes with TBST buffer, they were incubated with their respective secondary antibodies for $1 \mathrm{~h}$. The proteins were detected using an ECL system kit (Pierce Biotechnology, Beijing, China) and captured on lightsensitive X-ray film (Kodak, Shanghai, China). The optical densities were analyzed using the ImageJ software $(\mathrm{NIH}$, Bethesda, MD, USA).

\section{Statistical analysis}

All data was statistically analyzed using the statistical package for the social sciences (SPSS) version 18.0 (SPSS Inc., Chicago, IL, USA). The means of the different groups were compared using the Student's $t$-test and differences were considered statistically significant $\mathrm{p}<0.05$.

\section{Results}

\section{Effect of metformin on renal function}

Rats in the $I / R$ and $E$ groups showed significant increases in serum BUN and Cr levels compared with the $\mathrm{S}$ group rats $(\mathrm{p}<0.05)$. Furthermore, the $\mathrm{I} / \mathrm{R}$-induced increase improved following treatment with metformin; however, there was no significant difference between the $\mathrm{I} / \mathrm{R}$ and $\mathrm{E}$ groups (Table 1)

TABLE 1 - Metformin preconditioning reduced Jablonski grade and apoptosis index.

\begin{tabular}{ccccc}
\hline Group & BUN & Cr & Jablonski grade & Apoptosis index \% \\
\hline $\mathrm{S}$ & $5.01+0.16$ & $30.33+0.67$ & $0.33+0.21$ & $1.67+0.33$ \\
$\mathrm{I} / \mathrm{R}$ & $40.77+1.42^{*}$ & $326.5+10.22^{*}$ & $3.67+0.21^{*}$ & $34.50+1.12^{*}$ \\
$\mathrm{E}$ & $38.53+1.42^{* \#}$ & $297.3+11.44^{* \#}$ & $2.50+0.34^{* \# \#}$ & $27.50+1.12^{* \# \#}$ \\
\hline
\end{tabular}

${ }^{*} \mathrm{p}<0.05$ vs $\mathrm{S}$ group, ${ }^{\#} \mathrm{p}>0.05$ vs $\mathrm{I} / \mathrm{R}$ group, ${ }^{\#} \mathrm{p}<0.05$ vs I/R group. BUN, blood urea nitrogen; Cr, creatinine; $\mathrm{S}$, sham-operated; I/R, ischemia/perfusion; E, metformin. 


\section{Effect of metformin on renal histopathological changes}

The H\&E stained kidney tissue sections showed that there were no obvious glomerular and renal tubular necrotizing pathological changes in the $\mathrm{S}$ group. However, kidney $\mathrm{I} / \mathrm{R}$ resulted in significant renal injury, as evidenced by acute tubular necrosis, renal tubular expansion, renal tubular epithelial cell exfoliation, and development of proteinaceous casts. There were less renal tubular necrotizing changes in the group E than there were in the $\mathrm{I} / \mathrm{R}$ group. The Jablonski grade analysis of severe acute tubular necrosis results revealed significantly lower scores for the E group than for the I/R group. Metformin preconditioning significantly reduced the Jablonski grade and $\mathrm{AI}$ in group E compared with that of the $\mathrm{I} / \mathrm{R}$ group $(\mathrm{p}<0.05)$. Compared to $\mathrm{I} / \mathrm{R}$ group, Metformin preconditioning improved the renal dysfunction induced by $I / R$ injury, although there were no significant differences between groups $\mathrm{E}$ and $\mathrm{I} / \mathrm{R}(\mathrm{p}>0.05)$. Compared with group $\mathrm{S}$, the $\mathrm{I} / \mathrm{R}$ and E groups exhibited higher serum $\mathrm{Cr}$ and BUN levels as well as Jablonski grade and AI indices $(p<0.05$, Table 1 and Figure 1$)$. Furthermore, compared to the $\mathrm{S}$ group, the results of the TUNEL staining also revealed a significant increase in the AI of the E and $\mathrm{I} / \mathrm{R}$ groups $(\mathrm{p}<0.05)$, although that of group $\mathrm{E}$ was lower than that of the I/R group was ( $\mathrm{p}<0.05$, Table 1 , Figure 2$)$.

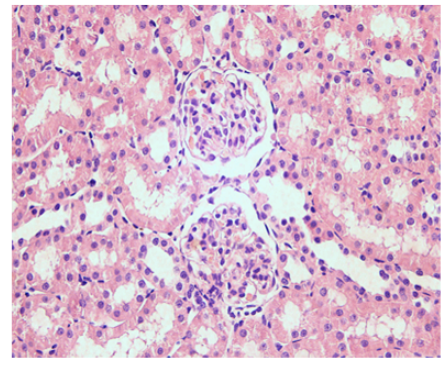

S group

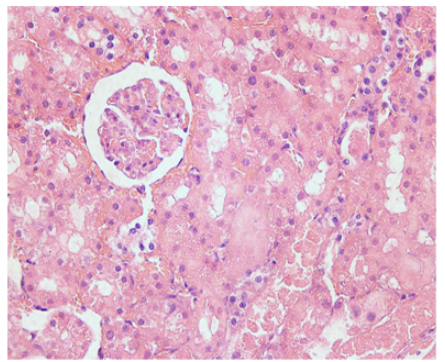

$\mathrm{I} / \mathrm{R}$ group

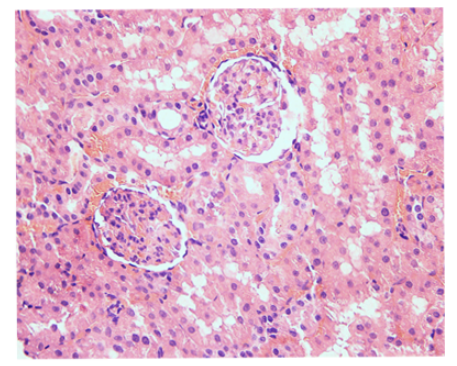

E group

FIGURE 1 - Metformin preconditioning improved morphological feature after renal ischemia/reperfusion (IR) injury. Compared to group S, I/R and E groups exhibited more tubular necrosis, renal tubular expansion, renal tubular epithelial cellular exfoliation, and development of proteinaceous casts. Renal tubular necrotizing pathological changes in group $\mathrm{E}$ were fewer than in I/R group. Jablonski grade of severe acute tubular necrosis was significantly lower in group $\mathrm{E}$ than in $\mathrm{I} / \mathrm{R}$ group $(\mathrm{p}<0.05$, magnification $\times 200)$. S, sham operated; $\mathrm{E}$, metformin.

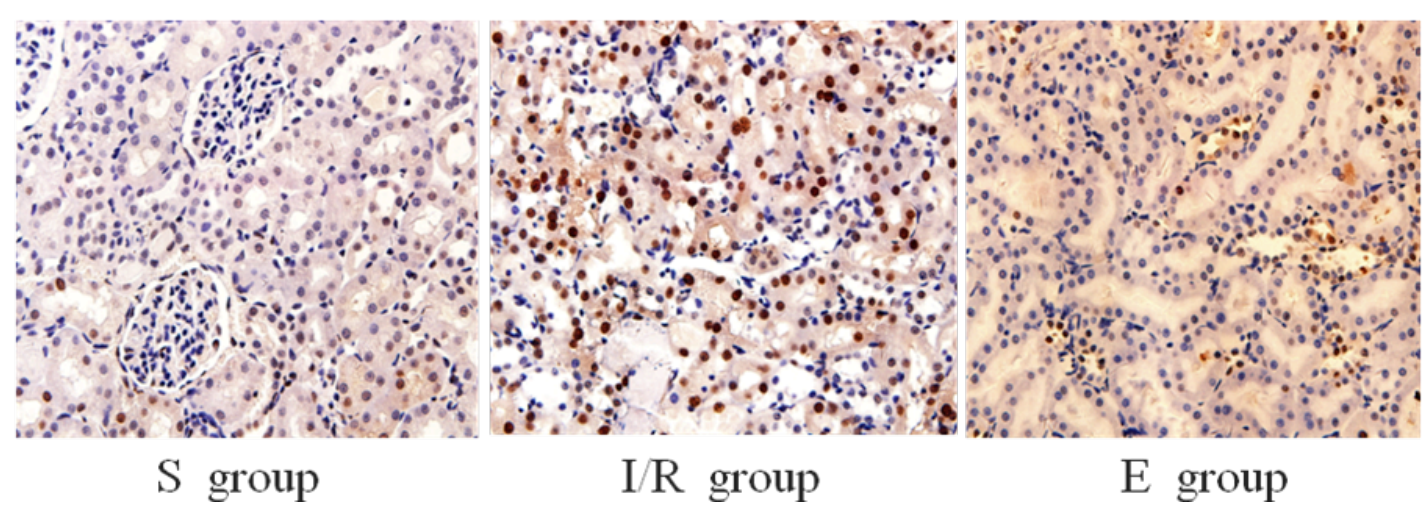

FIGURE 2 - Metformin preconditioning attenuated apoptosis of tubular epithelial cells. TUNEL staining shows apoptosis index increased significantly in groups $\mathrm{E}$ and $\mathrm{I} / \mathrm{R}$ compared with group $\mathrm{S}(\mathrm{p}<0.05)$. Apoptosis index of group $E$ was lower than that of $I / R$ group $(p<0.05$, magnification $\times 200)$. TUNEL, terminal deoxynucleotidyl transferase dUTP nick end labeling; $\mathrm{S}$, sham operated; $\mathrm{I} / \mathrm{R}$, ischemia reperfusion; $\mathrm{E}$, metformin. 
Effect of metformin on expression of pAMPK, COX-

2, and Caspase-3

The results of the immunohistochemistry analysis showed that the expression levels of COX-2 and Caspase- 3 in the $\mathrm{E}$ and $\mathrm{I} / \mathrm{R}$ groups were significantly higher than those in the $\mathrm{S}$ group were. However, the E group levels were much lower than those of the I/R group were (Figure 3). Furthermore, the western blot analysis revealed that the expressions of COX-2, Caspase-3, and $\mathrm{pAMPK}$ in groups $\mathrm{E}$ and $\mathrm{I} / \mathrm{R}$ were significantly higher than those in the $S$ group were $(p<0.05)$, while the expression of pAMPK was much more in group $E$ than it was in the $I / R$ group $(p<0.05)$. In addition, the expression levels of COX-2 and Caspase 3 were lower in group $\mathrm{E}$ than they were in the I/R group $(\mathrm{p}<0.05)$, However, there was no significant difference in the expression of AMPK between groups $\mathrm{E}$ and I/R ( $\mathrm{p}>0.05$, Figure 4$)$.

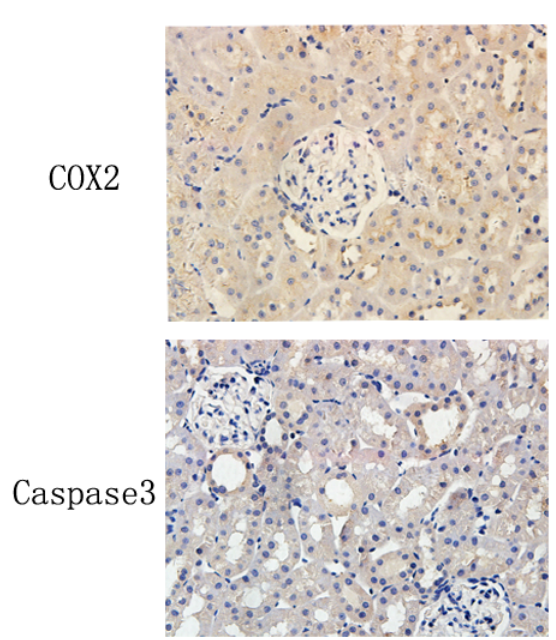

$\mathrm{S}$ group
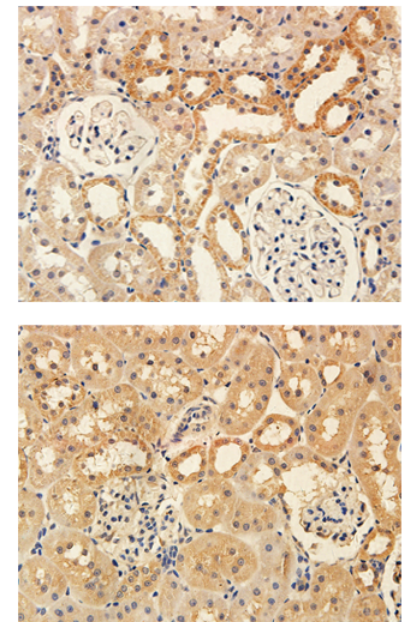

$\mathrm{I} / \mathrm{R}$ group
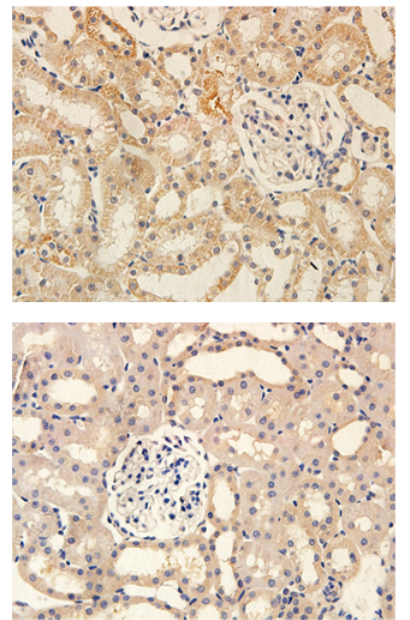

E group

FIGURE 3 - Effect of metformin preconditioning on cyclooxygenase (COX)-2 and Caspase 3 expressions after renal ischemia-reperfusion (I/R). Immunohistochemistry shows expression levels of COX2 and Caspase 3 in groups R and I/R were obviously higher than they were in group S. However, expression levels of COX2 and Caspase 3 in group E were much lower than they were in I/R group (magnification $\times 200$ ). S, sham operated; I/R, ischemia reperfusion; E, metformin.
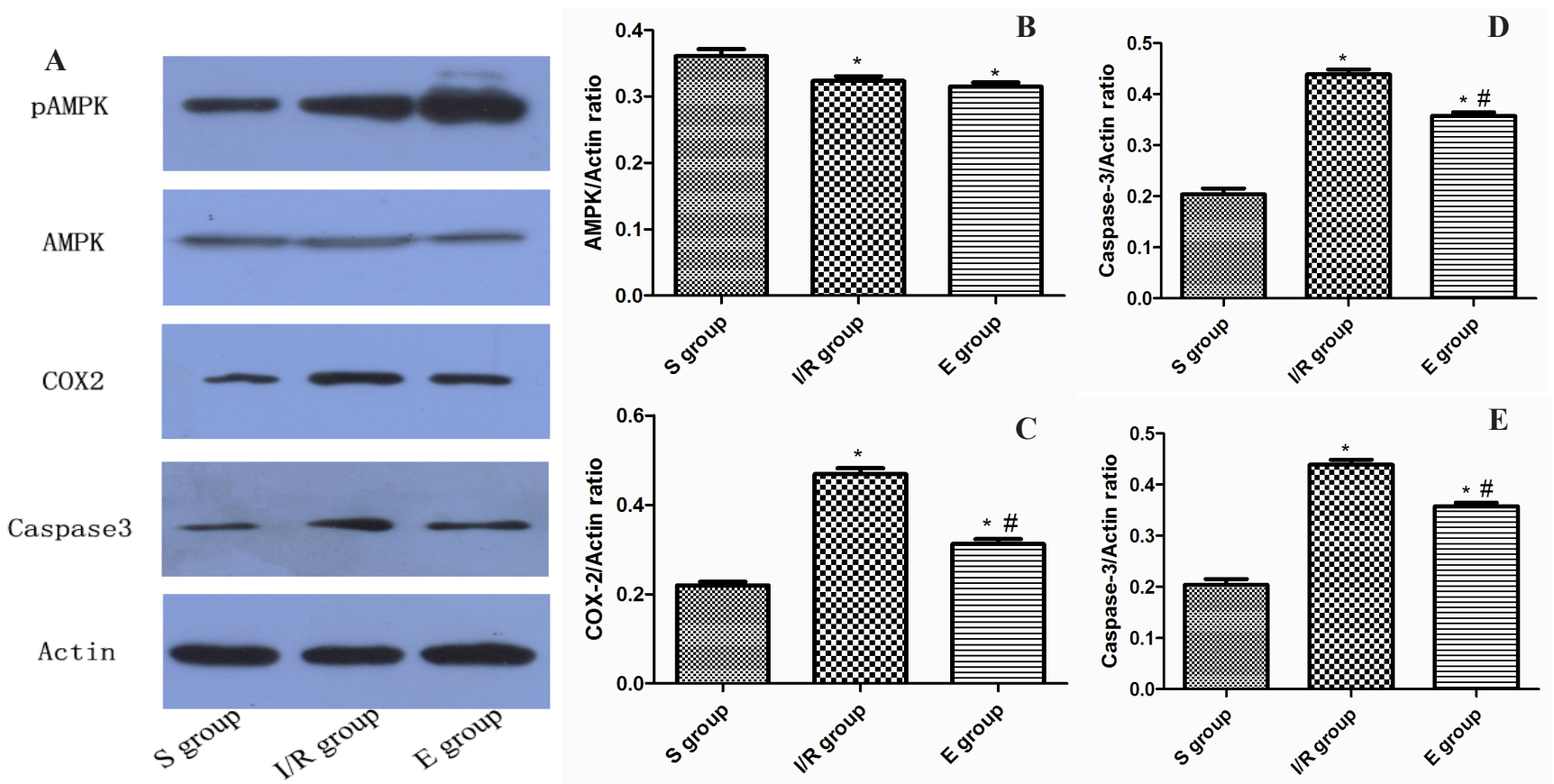

FIGURE 4 - Effect of metformin preconditioning on expression of adenosine monophosphate (AMP)-activated protein kinase (AMPK), phosphorylated (p)AMPK, cyclooxygenase (COX)-2 and Caspase 3. Expressions of COX-2, Caspase 3, and pAMPK in groups E and I/R were significantly higher than they were in group $\mathrm{S}(\mathrm{p}<0.05)$. Expression of pAMPK was significantly higher in group $\mathrm{E}$ than it was in $\mathrm{I} / \mathrm{R}$ group ( $<0.05)$, while levels of COX-2 and Caspase 3 were lower in group E than they were in I/R group $(\mathrm{p}<0.05)$. However, no significant differences were found in expression of AMPK between groups $\mathrm{E}$ and $\mathrm{I} / \mathrm{R}(\mathrm{p}>0.05)$. Bars represent means \pm S.E.M. $(\mathrm{n}=6),{ }^{*} \mathrm{p}<0.05$ vs $\mathrm{S}$ group, ${ }^{*} \mathrm{p}<0.05$ vs I/R group. S, sham operated; I/R, ischemia reperfusion; E, metformin. 


\section{Discussion}

$\mathrm{I} / \mathrm{R}$ injury is known to be induced by the ischemia that occurs after blood flow recovery and restoration to tissues and organs, which further aggravates the injury. It is generally accepted that $\mathrm{I} / \mathrm{R}$ injury is associated with a series of inflammatory reaction processes, which include endothelial cell activation, expression of adhesion molecules, adhesion, aggregation and activation of leukocytes and platelets, release of oxygen free radicals, and cellular calcium overload as well as apoptosis that is mediated by these processes. Acute kidney injury caused by $I / R$ is a clinical syndrome the leads to rapid kidney dysfunction and high mortality rates $^{13,14}$. However, the mechanisms underlying the development $\mathrm{I} / \mathrm{R}$ injury have not been fully elucidated.

The main characteristics of ischemic diseases include inflammatory responses, metabolic disorders, and cell necrosis ${ }^{15,16}$. AMPK is an evolutionarily conserved serine/threonine kinase and one of the key energy regulatory factors, which could inhibit constructive metabolism and promote the oxidation of fatty acid, glucose uptake, and glycolysis following its activation ${ }^{17}$. All these processes facilitate the increase in energy supply to the ischemic tissue.

There are several known physiological, pharmacological, and natural activators of AMPK, and a few of these are currently used clinically ${ }^{18,19}$ such as metformin. Accumulating evidence has shown that metformin inhibits the proliferation of prostate, ovarian, colon, and pancreatic cancer cells ${ }^{20-22}$. Furthermore, studies with metformin have shown that inflammatory mediators such as TNF- $\alpha$, IL-6, interferon (INF)- $\gamma$, and nuclear factor kappalight-chain-enhancer of activated B cells $(\mathrm{NF}-\kappa \mathrm{B})$ were decreased following supplementation with metformin ${ }^{23-25}$. Nevertheless, the effect of metformin on the kidney ischemia/reperfusion has not been studied yet. Therefore, in the present study, we investigated the effects of metformin on renal tubular epithelial cell apoptosis and inflammation in a rat model of kidney $\mathrm{I} / \mathrm{R}$ injury.

Metformin is an oral hypoglycemic agent that is commonly used in the treatment of type 2 diabetes mellitus. Furthermore, metformin has been shown to inhibit the activation of complex 1 in the Krebs cycle and upregulate the ratio of AMP/ ATP, which activates of AMPK ${ }^{26}$. Therefore, we further sought to determine if the effects of metformin in I/R injury are associated with the activation of AMPK signaling. Studies have shown that metformin protected the activity of Na-K-ATPase after ischemia and maintained the polarity of the renal tubular epithelial cells ${ }^{27}$ and, thereby, protected kidney tissue after IR injury perhaps by activating the AMPK cascade. In this study, we found that pretreatment with metformin increased the level of pAMPK.
Inflammatory responses are also important factors that contribute to worsening of renal function after ischemia-reperfusion. Studies show that AICAR (an AMPK agonist) inhibited inducible nitric oxide synthase (iNOS) and COX-2 produced by macrophages. COX-2 is the key enzyme in prostanoid synthesis, and an increase in its expression enhances the synthesis of proinflammatory factors such as prostaglandin (PG) E2 and PGI2, which might further aggravate the inflammatory response. In our study, we found that treatment with metformin reduced the levels of the inflammatory mediator, COX-2 and the proapoptotic factor, caspase- 3 in rats following I/R injury. Ariane Bischoff et al.$^{28}$ found that SC58125, a selective inhibitor of COX-2 alleviated renal tubular epithelial cell apoptosis after kidney I/R. We speculated that metformin reduced the activation of macrophages following ischemia and inhibited the expression of COX-2 and Caspase- 3 and, thereby, attenuated the inflammatory responses and apoptosis of the renal tubular epithelial cell. Furthermore, these effects may have been mediated by the activation of AMPK, and were beneficial in protecting the kidney tissue against I/R injury.

\section{Conclusions}

Metformin played a role in alleviating the inflammatory responses and apoptosis of renal tubular epithelial cell, which was beneficial in protecting the kidney from I/R injury. However, metformin did not significantly improve the kidney function in the acute phase of I/R injury. The results of this rodent study might be useful as a foundation for further research to elucidate the specific underlying protective mechanisms of metformin in renal $\mathrm{I} / \mathrm{R}$ injury.

\section{References}

1. Pruchnicki MC, Dasta JF. Acute renal failure in hospitalized patients:part I. Ann Pharmacother. 2002;36(7-8):1261-7. PMID: 12086561 .

2. El Messaoudi S, Rongen GA, de Boer RA, Riksen NP. The cardioprotective effects of metformin. Curr Opin Lipidol. 2011;22(6):445-53. PMID: 21897229.

3. di Mari JF, Davis R, Safirstein RL. MAPK activation determines renal epithelial cell survival during oxidative injury. Am J Physiol. 1999;277(2 Pt 2):F195-203. PMID: 10444573.

4. Lin A, Sekhon C, Sekhon B, Smith A, Chavin K, Orak J, Singh I, Singh A. Attenuation of ischemia-reperfusion injury in a canine model of autologous renal transplantation. Transplantation. 2004;78(5):654-9. PMID: 15371664.

5. Kanellis J, Kandane RK, Etemadmoghadam D, Fraser SA, Mount PF, Levidiotis V, Kemp BE, Power DA. Activators of the energy sensing kinase AMPK inhibit random cell movement and chemotaxis in U937 cells. Immunol Cell Biol. 2006;84(1):6-12. PMID: 16405649. 
6. Sag D, Carling D, Stout RD, Suttles J. Adenosine 5'-monophosphateactivated protein kinase promotes macrophage polarization to an antiinflammatory functional phenotype. J Immunol. 2008;181(12):863341. PMID: 19050283

7. Zhao X, Zmijewski JW, Lorne E, Liu G, Park YJ, Tsuruta Y, Abraham E. Activation of AMPK attenuates neutrophil proinflammatory activity and decreases the severity of acute lung injury. Am J Physiol Lung Cell Mol Physiol. 2008;295(3):L497-504. PMID: 18586954.

8. Arias-Negrete S, Keller K, Chadee K. Proinflammatory cytokines regulate cyclooxygenase-2 mRNA expression in human macrophages. Biochem Biophys Res Commun. 1995;208(2):582-9. PMID: 7695610.

9. Diaz A, Chepenik KP, Korn JH, Reginato AM, Jimenez SA. Differential regulation of cyclooxygenases 1 and 2 by interleukin- 1 beta, tumor necrosis factor-alpha, and transforming growth factorbeta 1 in human lung fibroblasts. Exp Cell Res. 1998;241(1):222-9. PMID: 9633531.

10. Chatterjee PK, Brown PA, Cuzzocrea S, Zacharowski K, Stewart $\mathrm{KN}$, Mota-Filipe H, McDonald MC, Thiemermann C. Calpain inhibitor-1 reduces renal ischemia/reperfusion injury in the rat. Kidney Int. 2001;59(6):2073-83. PMID: 11380809.

11. Matsuyama M, Yoshimura R, Hase T, Kawahito Y, Sano H, Nakatani T. Study of cyclooxygenase-2 in renal ischemia-reperfusion injury. Transplant Proc. 2005;37(1):370-2. PMID: 15808647.

12. Jablonski P, Howden BO, Rae DA, Birrell CS, Marshall VC, Tange J. An experimental model for assessment of renal recovery from warm ischemia. Transplantation. 1983;35(3):198-204. PMID: 6340272.

13. Kellum JA, Unruh ML, Murugan R. Acute kidney injury. BMJ Clin Evid. 2011;2011. PMID: 21443811.

14. Hoste EA, Clermont G, Kersten A, Venkataraman R, Angus DC, De Bacquer D, Kellum JA. RIFLE criteria for acute kidney injury are associated with hospital mortality in critically ill patients: a cohort analysis. Crit Care. 2006;10(3):R73. PMID: 16696865.

15. Zhao ZQ, Corvera JS, Halkos ME, Kerendi F, Wang NP, Guyton RA, Vinten-Johansen J. Inhibition of myocardial injury by ischemic postconditioning during reperfusion: comparison with ischemic preconditioning. Am J Physiol Heart Circ Physiol. 2003;285(2):H579-88. PMID: 12860564.

16. Hardie DG, Sakamoto K. AMPK: a key sensor of fuel and energy status in skeletal muscle. Physiology (Bethesda). 2006;21:48-60. PMID: 16443822

17. Krishan S, Richardson DR, Sahni S Adenosine monophosphate-activated kinase and its key role in catabolism: structure, regulation, biologicalactivity, and pharmacological activation. Mol Pharmacol. 2015;87(3):36377. PMID: 25422142.

18. Corton JM, Gillespie JG, Hawley SA, and Hardie DG. 5-aminoimidazole-4- carboxamide ribonucleoside. A specific method for activating AMP-activated protein kinase in intact cells? Eur J Biochem. 1995;229(2):558-65. PMID: 7744080.

19. Zhou G, Myers R, Li Y, Chen Y, Shen X, Fenyk-Melody J, Wu M, Ventre J, Doebber T, Fujii N, Musi N, Hirshman MF, Goodyear LJ, Moller DE. Role of AMP-activated protein kinase in mechanism of metformin action. J Clin Invest. 2001;108(8):1167-74. PMID: 11602624

20. Buzzai M, Jones RG, Amaravadi RK, Lum JJ, DeBerardinis RJ, Zhao F, Viollet B, Thompson CB. Systemic treatment with the antidiabetic drug metformin selectively impairs p53-deficient tumor cell growth. Cancer Res. 2007;67(14):6745-52. PMID: 17638885.

21. Zhuang, Y., Miskimins, W.K. Cell cycle arrest in Metformin treated breast cancer cells involves activation of AMPK, downregulation of cyclin D1, and requires p27Kip1 or p21Cip1. J Mol Signal. 2008;3:18. PMID: 19046439.
22. Ben Sahra I, Laurent K, Loubat A, Giorgetti-Peraldi S, Colosetti P, Auberger P, Tanti JF, Le Marchand-Brustel Y, Bost F. The antidiabetic drug metformin exerts an antitumoral effect in vitro and in vivo through a decrease of cyclin D1 level. Oncogene. 2008;27(25):3576-86. PMID: 18212742.

23. Bergheim I, Luyendyk JP, Steele C, Russell GK, Guo L, Roth RA, Arteel GE. Metformin prevents endotoxin-induced liver injury after partial hepatectomy. J Pharmacol Exp Ther. 2006;316(3):1053-61. PMID: 16322356.

24. Chen SQ, Liu Q, Sun H, Tang L, Deng JC. Effects of metformin on fatty liver in insulin-resistant rats. Zhonghua Gan Zang Bing Za Zhi. 2005;13(12):915-8. PMID: 16381638

25. Hattori Y, Suzuki K, Hattori S, Kasai K. Metformin inhibits cytokineinduced nuclear factor kappaB activation via AMP-activated protein kinase activation in vascular endothelial cells. Hypertension. 2006;47(6):1183-8. PMID: 16636195.

26. Pene F, Claessens YE, Muller O, Viguié F, Mayeux P, Dreyfus F, Lacombe C, Bouscary D. Role of the phosphatidylinositol 3-kinase/Akt and mTOR/P70S6- kinase pathways in the proliferation and apoptosis in multiple myeloma. Oncogene. 2002;21(43):658797. PMID: 12242656.

27. Seo-Mayer PW, Thulin G, Zhang L, Alves DS, Ardito T, Kashgarian M, Caplan MJ. Preactivation of AMPK by metformin may ameliorate the epithelial cell damage caused by renal ischemia. Am J Physiol Renal Physiol. 2011;301(6):F1346-57. PMID: 21849490.

28. Bischoff A, Bucher M, Gekle M, Sauvant C. Differential effect of COX1 and COX2 inhibitors on renal outcomes following ischemic acute kidney injury. Am J Nephrol. 2014;40(1):1-11. PMID: 24943263.

\section{Correspondence:}

Xiu-heng Liu

Department of Urology, Renmin Hospital of Wuhan University

Jiefang Road 238 Wuhan, Hubei, China, 430060

Phone: (86)027-88041911

Fax: (86)027-88042292

xhliu2014@126.com

Received: May 11, 2015

Review: July 13, 2015

Accepted: Aug 122015

Conflict of interest: none

Financial sources: National Natural Science Foundation of China (No. 81400753) and Natural Science Foundation of Hubei Province (No. 2014CFB362)

${ }^{1}$ Research performed at Key Laboratory, Hubei Province for Digestive System Disease, Department of Gastroenterology, Renmin Hospital, Wuhan University, Hubei, China. 